\title{
Cerebral Microbleeds and Functional Outcomes after Ischemic Stroke
}

\author{
Tae-Won Kim, Seung-Jae Lee, Jaseong Koo, Hyun-Seok Choi, Jeong-Wook Park, \\ Kwang-Soo Lee, Joong-Seok Kim
}

\begin{abstract}
Background: Whether an association exists between cerebral microbleeds (CMBs) and functional recovery after ischemic stroke is unclear. We aimed to evaluate the association between CMBs and functional outcome after acute ischemic stroke. Methods: Consecutive patients with acute stroke were enrolled, and all patients were stratified into good and poor functional outcome groups at discharge and 6 months after ischemic stroke by using a modified Rankin Scale score. Cardiovascular risk factors, CMBs, and white matter hyperintensities were compared between these two outcome groups. Logistic regression analysis was used to estimate the risk of poor functional outcomes. Results: A total of 225 patients were enrolled, 121 of whom were classified as having a good functional outcome at discharge and 142 as having a good 6-month functional outcome. The presence of CMBs was associated with a poor functional outcome at discharge [CMBs (+) patients in poor vs. good functional group; $48.1 \%$ vs. 30.6\%; $p=0.007]$ and 6 months [53.0\% vs. 30.3\%; $p=0.001]$. After adjustment for confounding factors, only the presence of infratentorial CMBs was associated with a poor functional outcome at discharge and 6 months. The poor functional outcome group had more CMBs than the good outcome group at 6 months. Conclusions: Infratentorial cerebral microbleeds were significantly associated with worse functional outcomes not only in the early phase of ischemic stroke but also in the chronic phase. These findings suggest that the presence of infratentorial CMBs can predict poor functional outcome after acute ischemic stroke.
\end{abstract}

RÉSUMÉ: Microsaignements cérébraux et issue clinique après un accident vasculaire cérébral ischémique. Contexte: On ne sait pas s'il existe une association entre les microsaignements cérébraux (MSC) et la récupération fonctionnelle après un accident vasculaire cérébral ischémique (AVCI). Le but de l'étude était d'évaluer l'association entre les MSC et l'issue fonctionnelle après un AVCI. Méthode: L'étude a porté sur des patients consécutifs admis pour un AVC aigu. Ils ont été séparés en deux groupes, selon que l'issue clinique fonctionnelle, évaluée au moyen de l'échelle modifiée de Rankin, était bonne ou mauvaise au moment du congé hospitalier et 6 mois après l'AVCI. Les facteurs de risque cardiovasculaire, les MSC et les zones d'hyperintensité ont été comparés entre les deux groupes. L'analyse de régression logistique a été utilisée pour estimer le risque que l'issue fonctionnelle soit mauvaise. Résultats: Deux cent vingt-cinq patients ont été admis à l'étude dont 121 ont été classifiés dans le groupe dont l'issue fonctionnelle était favorable au moment du congé hospitalier et 142 dans le groupe dont l'une issue fonctionnelle était favorable 6 mois après l'AVCI. La présence de MSC était associée à un résultat fonctionnel défavorable au moment du congé hospitalier [patients MSC (+) dans le groupe ayant une issue fonctionnelle défavorable par rapport à ceux dont l'issue fonctionnelle était favorable : 48,1\% par rapport à 30,6\%; $p=0,007]$ et à 6 mois $[53,0 \%$ par rapport à 30,3\%; $p=0,001]$. Après correction pour les facteurs de confusion, seule la présence de MSC sous-tentoriels était associée à une issue fonctionnelle défavorable au moment du congé hospitalier et 6 mois après l'AVC. Le groupe de patients dont l'issue fonctionnelle était défavorable avaient plus de MSC que le groupe dont l'issue était favorable 6 mois après l'AVC. Conclusions: Les MSC sous-tentoriels étaient associés de façon significative à une issue fonctionnelle moins bonne, non seulement au cours de la phase précoce de mais aussi au cours de la phase chronique de l'AVCI. La présence de MSC sous-tentoriels pourrait prédire une issue fonctionnelle défavorable après un AVCI.

Keywords: Cerebral microbleeds, functional outcomes, acute, ischemic stroke, white matter hyperintensities, infratentorial doi:10.1017/cjn.2014.19

Can J Neurol Sci. 2014; 41: 577-582

\section{INTRODUCTION}

Ischemic stroke often leads to disabling sequelae or even death. Early prediction of functional outcomes after acute ischemic stroke could facilitate appropriate treatment and management. Several clinical factors have been identified as predictors of outcome, including age, sex, initial stroke severity, white matter hyperintensities (WMH), and vascular risk factors. ${ }^{1-3}$

Cerebral microbleeds (CMBs) are small foci of chronic hemorrhages that have been increasingly detected with the widespread application of MRI techniques that are sensitive to magnetic susceptibility. CMBs are more prevalent in patients with ischemic stroke than healthy elderly subjects and are associated

From the Department of Neurology (TWK, JK, JWP, KSL, JSK), College of Medicine, Catholic University of Korea, Seoul, Korea; Department of Neurology (SJL), Sejong

General Hospital, Bucheon, Korea; Department of Radiology (HSC), College of Medicine, Catholic University of Korea, Seoul, Korea.

Received February 11, 2014. Final Revisions Submitted April 3, 2014. Correspondence to: Joong-Seok Kim, Department of Neurology, Seoul St. Mary's Hospital, Catholic University of Korea, Seocho-gu, Seoul 137-701, Korea.

Email: neuronet@catholic.ac.kr. 
with increased risk of intracerebral hemorrhage, worse cognitive function, and poststroke depression. ${ }^{4-7}$

More commonly observed in patients with small-vessel disease than subgroups with large-vessel atherosclerosis or cardioembolism, ${ }^{8} \mathrm{CMBs}$ are also a marker of cerebral small-vessel disease along with lacunes and WMH. ${ }^{5}$ Although both lacunes and WMH are associated with poor functional outcomes and disability, ${ }^{2,9-11}$ whether CMBs are associated with poor functional outcomes after ischemic stroke has not been verified.

We tested the hypothesis that preexisting CMBs are associated with poor functional outcomes after ischemic stroke. We examined the associations between CMBs and functional outcomes at discharge and 6 months after acute ischemic stroke.

\section{MeTHODS}

\section{Patients}

The ethics committee of Seoul St. Mary's Hospital approved this study. We studied consecutive patients with acute ischemic stroke who were admitted to the Department of Neurology at Seoul St. Mary's Hospital between May 1, 2011, and April 30, 2012. Clinical information obtained included age, sex, history of hypertension, diabetes mellitus, dyslipidemia, ischemic heart disease, previous stroke, and current cigarette smoking. All patients underwent clinical evaluation, including neurological examination, laboratory tests, chest radiography, electrocardiography, $24 \mathrm{~h}$ Holter monitoring, brain MRI, and contrastenhanced magnetic resonance angiography (MRA). Stroke was defined on the basis of clinical history and the neurological examination with compatible new lesions on MRI. Patients were excluded if had any of the following conditions applied: (1) preexisting significant disability (defined as modified Rankin scale $[\mathrm{mRS}] \geq 2$ from any conditions); (2) history of stroke in the past 3 months; (3) hemorrhagic stroke; (4) transient neurologic symptoms without ischemic lesions on diffusion-weighted imaging; (5) received intravenous fibrinolysis or endovascular recanalization reperfusion therapy; (6) physical illness that was life-threatening or interfered with recovery from ischemic stroke; (7) subarachnoid hemorrhage, or symptoms suggestive of same even if CT scan was normal; and (8) any of the following comorbid neurological diseases: dementia, Parkinson's disease or atypical Parkinsonism, brain tumor, intracranial vascular malformations, peripheral nerve or muscle diseases.

\section{Assessment of Stroke Severity and Functional Outcomes}

Severities and functional outcomes of stroke were assessed at admission, $24 \mathrm{~h}$ after admission, discharge, and 6 months after admission. Assessments used the National Institutes of Health Stroke Scale (NIHSS; scores range from 0 to 42, with higher scores indicating greater deficits) ${ }^{12}$ and the mRS (scores range from 0 [no symptoms] to 6 [death]). ${ }^{13}$ All assessments were performed by study investigators unaware of all clinical and image data.

\section{Brain MRI}

We executed multisequence MRI protocols within $24 \mathrm{~h}$ of admission on a 3-Tesla scanner (Verio, Siemens Medical Solutions, Erlangen, Germany). The conventional MRI protocol consisted of transverse T2/T1-weighted, fluid-attenuated inversion recovery sequences and sagittal $\mathrm{T} 1$ with $5-\mathrm{mm}$ slices. Diffusion-weighted imaging and three-dimensional time-of-flight MRA of the intracranial arteries and contrast-enhanced MRA of the head and neck were also performed on the same system. A T2*-weighted gradient-recalled echo sequence with high spatial resolution and long echo time was used to detect microbleeds.

\section{Analysis of CMBs}

All gradient-recalled echo scans were reviewed by an experienced neuroradiologist (H.S.C.) who was unaware of all clinical data. Microbleeds were defined as focal areas of very low signal intensity. Signal voids caused by sulcal vessels, symmetric calcifications in the basal ganglia and/or choroid plexus, pineal calcifications, and signal averaging from bone were excluded. ${ }^{13}$

Size definitions of CMBs (maximum diameter) are not consistent among previous studies. Nonetheless, an upper diameter limit of $10 \mathrm{~mm}$ was applied in almost $80 \%$ of subjects in previous CMB studies. ${ }^{4,14}$ Therefore, we used an upper diameter limit of $10 \mathrm{~mm}$ and classified location of CMBs as lobar, deep, or infratentorial. ${ }^{15}$

\section{WMH Scoring}

We rated WMH by using the semiquantitative visual rating system described by Scheltens and colleagues. ${ }^{16}$ This rating scale provides four sum scores in a semiquantitative manner: periventricular hyperintensities (0-6), deep WMH (0-24), basal ganglia hyperintensities (0-30), and infratentorial hyperintensities (0-30). Lacunes (well-defined hypointense lesions $>2 \mathrm{~mm}$ with a hyperintense rim on fluid-attenuated inversion recovery images), perivascular spaces (well-defined rounded area with the same signal characteristics as CSF), and old territorial infarcts (asymmetric ischemic lesions involving large-artery brain territory) were not counted.

\section{Assessment of Demographic and Clinical Covariates}

History of cardiovascular risk factors such as hypertension, diabetes, dyslipidemia, previous stroke, and ischemic heart disease were obtained from patients or their caregiver, or by medical records, as appropriate. Stroke location by hemisphere was divided into left, right, and bilateral by using brain diffusion-weighted MRI. Potential risk factors for stroke outcomes that we considered covariates were age, sex, initial NIHSS, stroke location by hemisphere, history of hypertension, diabetes, dyslipidemia, previous stroke, ischemic heart disease, and WMH. ${ }^{2}$

\section{Statistical Analyses}

Dependent variables were functional outcomes measured by the $\mathrm{mRS}$ at both discharge and 6 months after ischemic stroke. Patients' outcomes were dichotomized into good or poor functional outcomes by using a mRS score cutoff of 2 (slight disability) or 3 (able to walk without help but requiring some help in daily living activities), in accordance with previous studies. . $^{27,18}$

Demographic and clinical characteristics and the presence of CMBs in either the whole brain area or in each categorized anatomical location were compared between the two groups by using independent-sample $t$ tests, $\chi^{2}$ tests, or Fisher's exact tests as appropriate. Associations between WMH and CMBs were determined using Spearman's rank correlation. Associations between 


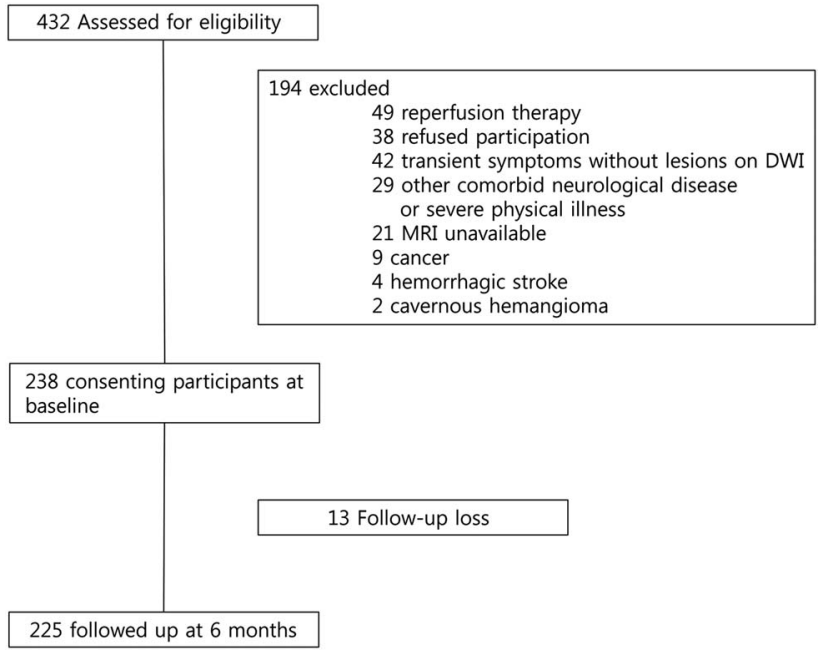

Figure 1: Flow diagram for recruitment. DWI, diffusion-weighted images.

the number of CMBs in either the whole brain area or specific anatomical locations and poor functional outcome were also determined. Finally, logistic multivariable regression analysis of all variables with a probability value less than 0.2 in the univariate analysis was performed. Because the number of CMBs was highly skewed, consistent with previous CMBs studies, ${ }^{5,19,20}$ we classified CMBs as present or absent in each anatomical region in the logistic multivariable regression analysis. For all tests, we set the significance level at $p<0.05$.

\section{RESULTS}

Figure 1 shows a flow diagram of patients included in our study. Of 432 patients initially assessed, 194 were excluded on the basis of applied inclusion and exclusion criteria. Two hundred thirty-eight patients with acute ischemic stroke were evaluated and discharged from the hospital. Of these, 13 patients were lost to follow-up.

Among the 225 ischemic stroke patients, 123 (54.7\%) were male. Mean ( \pm standard deviation) age was $67.6 \pm 13.7$ years. One hundred forty-one patients $(62.7 \%)$ had hypertension, $64(28.4 \%)$ had diabetes, 87 (38.7\%) had dyslipidemia, 19 (8.4\%) had ischemic heart disease, and 44 (19.6\%) had a history of stroke. Median time between symptom onset and examination was $17 \mathrm{~h}$. Mean time from admission to hospital discharge was $7.3 \pm 8.7$ days (median, 4 days). Initial NIHSS and mRS averaged 5.2 \pm 5.5 and $2.9 \pm 1.4$, respectively. WHM were observed in 184 patients $(81.8 \%)$ and the average WMH score was 8.6 \pm 8.6. WMH were most prevalent in the lobar $(76 \%)$ area, followed by the periventricular $(68 \%)$, deep $(32.9 \%)$, and infratentorial $(9.8 \%)$ areas (Table 1$)$.

Table 1: Demographics and laboratory data of patients with and without CMBs

\begin{tabular}{|c|c|c|c|c|}
\hline Variable & Total & CMB- $(n=138)$ & $\mathrm{CMB}+(n=87)$ & $p$ \\
\hline Age, years & $67.6 \pm 13.7$ & $65.5 \pm 14.4$ & $71.1 \pm 11.9$ & $0.003 * *$ \\
\hline Sex, male & $123(54.7 \%)$ & $74(53.6 \%)$ & $49(56.3 \%)$ & 0.692 \\
\hline Hypertension & $141(62.7 \%)$ & $77(55.8 \%)$ & $64(73.6 \%)$ & $0.007 * *$ \\
\hline Diabetes mellitus & $64(28.4 \%)$ & $44(31.9 \%)$ & $20(23.0 \%)$ & 0.150 \\
\hline Dyslipidemia & $87(38.7 \%)$ & $48(34.8 \%)$ & $39(44.8 \%)$ & 0.132 \\
\hline Ischemic heart disease & $19(8.4 \%)$ & $12(8.7 \%)$ & $7(8.0 \%)$ & 0.864 \\
\hline Atrial fibrillation & $53(23.6 \%)$ & $30(21.7 \%)$ & $23(26.4 \%)$ & 0.419 \\
\hline Previous stroke & $44(19.6 \%)$ & $21(15.2 \%)$ & $23(26.4 \%)$ & 0.057 \\
\hline Previous use of antiplatelet agents & $48(21.3 \%)$ & $29(21.0 \%)$ & $19(21.8 \%)$ & 0.883 \\
\hline Previous use of anticoagulant agents & $4(1.8 \%)$ & $1(0.7 \%)$ & $3(3.4 \%)$ & 0.301 \\
\hline Previous use of statin & $12(5.3 \%)$ & $7(5.1 \%)$ & $5(5.7 \%)$ & 1.000 \\
\hline Total cholesterol $(\mathrm{mg} / \mathrm{dL})$ & $184.6 \pm 40.1$ & $182.7 \pm 40.1$ & $187.5 \pm 40.8$ & 0.390 \\
\hline $\mathrm{LDL}(\mathrm{mg} / \mathrm{dL})$ & $115.1 \pm 35.1$ & $113.7 \pm 34.4$ & $117.3 \pm 36.4$ & 0.467 \\
\hline Fasting serum glucose $(\mathrm{mg} / \mathrm{dL})$ & $112.6 \pm 32.8$ & $112.0 \pm 32.0$ & $114.0 \pm 34.1$ & 0.738 \\
\hline Presence of WMH & $184(81.8 \%)$ & $106(76.8 \%)$ & $78(89.7 \%)$ & $0.015^{*}$ \\
\hline WMH score & $8.6 \pm 8.6$ & $6.1 \pm 7.3$ & $12.5 \pm 9.0$ & $<0.001 * *$ \\
\hline Mean NIHSS at admission & $5.2 \pm 5.5$ & $4.8 \pm 5.1$ & $5.9 \pm 6.1$ & 0.153 \\
\hline Mean mRS at admission & $2.9 \pm 1.4$ & $2.8 \pm 1.4$ & $3.0 \pm 1.4$ & 0.190 \\
\hline Mean $\mathrm{mRS}$ at discharge & $2.4 \pm 1.6$ & $2.1 \pm 1.6$ & $2.8 \pm 1.7$ & $0.005^{* *}$ \\
\hline Mean mRS at 6 months after stroke & $2.0 \pm 2.0$ & $1.7 \pm 1.9$ & $2.6 \pm 2.0$ & $<0.001 * *$ \\
\hline
\end{tabular}

CBM; cerebral microbleed, LDL; low-density lipoprotein, WMH; white matter hyperintensity, NIHSS; National Institutes of Health Stroke Scale, mRS: modified Rankin scale.

Values represent mean with standard deviation or numbers of patients with percentage in parentheses.

Analyses were performed by independent-sample $t$ tests and $\chi^{2}$ tests as appropriate.

$*, p<0.05 ; * *, p<0.01$. 
Table 2: Baseline characteristics by stroke outcome status at discharge and at 6 months

\begin{tabular}{|c|c|c|c|c|c|c|c|}
\hline \multirow[b]{2}{*}{ Variable } & \multirow[b]{2}{*}{$\begin{array}{c}\text { Total } \\
\text { patients }\end{array}$} & \multicolumn{3}{|c|}{ At discharge } & \multicolumn{3}{|c|}{ At 6 months } \\
\hline & & $\begin{array}{c}\text { Good outcome }^{\mathrm{a}} \\
\quad(n=121)\end{array}$ & $\begin{array}{c}\begin{array}{c}\text { Poor outcome } \\
(n=104)\end{array} \\
\end{array}$ & $p^{\mathbf{b}}$ & $\begin{array}{c}\text { Good outcome }{ }^{\mathrm{a}} \\
\quad(n=142)\end{array}$ & $\begin{array}{c}\text { Poor outcome } \\
(n=83)\end{array}$ & $p^{\mathbf{b}}$ \\
\hline Age, years & $67.6 \pm 13.7$ & $64.7 \pm 14.2$ & $71.1 \pm 12.4$ & $<0.001 * *$ & $64.0 \pm 14.0$ & $73.9 \pm 10.7$ & $<0.001 * *$ \\
\hline Sex, male & $123(54.7 \%)$ & $65(53.7 \%)$ & $58(55.8 \%)$ & 0.758 & $84(59.2 \%)$ & $39(47.0 \%)$ & 0.077 \\
\hline Hypertension & $141(62.7 \%)$ & $73(60.3 \%)$ & $68(65.4 \%)$ & 0.435 & $83(58.5 \%)$ & $58(69.9 \%)$ & 0.087 \\
\hline Diabetes & $64(28.4 \%)$ & $35(28.9 \%)$ & $29(27.9 \%)$ & 0.863 & $40(28.2 \%)$ & $24(28.9 \%)$ & 0.905 \\
\hline Dyslipidemia & $87(38.7 \%)$ & $46(38.0 \%)$ & $41(39.4 \%)$ & 0.829 & $52(36.6 \%)$ & $35(42.2 \%)$ & 0.410 \\
\hline Ischemic heart disease & $19(8.4 \%)$ & $9(7.4 \%)$ & $10(9.6 \%)$ & 0.558 & $12(8.5 \%)$ & $7(8.4 \%)$ & 0.996 \\
\hline Previous stroke & $44(19.6 \%)$ & $18(14.9 \%)$ & $26(25.0 \%)$ & 0.056 & $21(14.8 \%)$ & $23(27.7 \%)$ & $0.018 *$ \\
\hline WMH score & $8.6 \pm 8.6$ & $6.8 \pm 6.8$ & $10.6 \pm 9.8$ & $0.001 * *$ & $6.4 \pm 6.6$ & $12.4 \pm 10.1$ & $<0.001 * *$ \\
\hline $\begin{array}{l}\text { Initial NIHSS on } \\
\text { admission }\end{array}$ & $5.2 \pm 5.5$ & $3.1 \pm 3.7$ & $7.8 \pm 6.3$ & $<0.001 * *$ & $3.4 \pm 3.9$ & $8.4 \pm 6.5$ & $<0.001 * *$ \\
\hline Initial mRS on admission & $2.9 \pm 1.4$ & $2.1 \pm 1.2$ & $3.8 \pm 0.8$ & $<0.001 * *$ & $2.4 \pm 1.3$ & $3.8 \pm 1.0$ & $<0.001 * *$ \\
\hline \multicolumn{8}{|l|}{ Stroke location } \\
\hline Right & $108(48.0 \%)$ & $56(46.3 \%)$ & $52(50.0 \%)$ & 0.141 & $65(45.8 \%)$ & $43(51.8 \%)$ & 0.203 \\
\hline Left & $104(46.2 \%)$ & $61(50.4 \%)$ & $43(41.3 \%)$ & & $71(50.0 \%)$ & $33(39.8 \%)$ & \\
\hline Bilateral & $13(5.8 \%)$ & $4(3.3 \%)$ & $9(8.7 \%)$ & & $6(4.2 \%)$ & $7(8.4 \%)$ & \\
\hline \multicolumn{8}{|l|}{ Microbleeds } \\
\hline Presence of CMBs & $87(38.7 \%)$ & $37(30.6 \%)$ & $50(48.1 \%)$ & $0.007 * *$ & $43(30.3 \%)$ & $44(53.0 \%)$ & $0.001 * *$ \\
\hline Lobar CMBs & $56(24.9 \%)$ & $21(17.4 \%)$ & $35(33.7 \%)$ & $0.005 * *$ & $24(16.9 \%)$ & $32(38.6 \%)$ & $<0.001 * *$ \\
\hline Deep CMBs & $55(24.4 \%)$ & $26(21.5 \%)$ & $29(27.9 \%)$ & 0.266 & $30(21.1 \%)$ & $25(30.1 \%)$ & 0.130 \\
\hline Infratentorial CMBs & $40(17.8 \%)$ & $14(11.6 \%)$ & $26(25.0 \%)$ & $0.009 * *$ & $15(10.6 \%)$ & $25(30.1 \%)$ & $<0.001 * *$ \\
\hline Mean numbers of CMBs & $2.0 \pm 4.7$ & $1.6 \pm 4.3$ & $2.5 \pm 5.1$ & 0.133 & $1.4 \pm 4.0$ & $3.0 \pm 5.5$ & $0.025^{*}$ \\
\hline Lobar CMBs, No. & $0.6 \pm 1.7$ & $0.5 \pm 1.7$ & $0.8 \pm 1.6$ & 0.150 & $0.5 \pm 1.7$ & $0.9 \pm 1.6$ & $0.045^{*}$ \\
\hline Deep CMBs, No. & $0.9 \pm 2.5$ & $0.8 \pm 2.2$ & $1.1 \pm 2.8$ & 0.270 & $0.7 \pm 2.1$ & $1.4 \pm 3.0$ & 0.076 \\
\hline Infratentorial CMBs, No. & $0.4 \pm 1.4$ & $0.3 \pm 1.3$ & $0.6 \pm 1.5$ & 0.156 & $0.3 \pm 1.1$ & $0.7 \pm 1.6$ & $0.029 *$ \\
\hline
\end{tabular}

WMH; white matter hyperintensity, NIHSS; National Institutes of Health Stroke Scale, mRS: modified Rankin scale, CMB; cerebral microbleed.

Values represent mean with standard deviation or numbers of patients with percentage in parentheses.

${ }^{\mathrm{a}}$ Good functional outcome, mRS 0-2; poor functional outcome, $\mathrm{mRS} \geq 3$.

${ }^{\mathrm{b}} p$ value using independent-sample $t$ tests, $\chi^{2}$ tests, or Fisher's exact tests as appropriate.

$*, p<0.05 ; * *, p<0.01$.

We found CMBs in 87 patients $(38.7 \%)$, the presence of which was significantly related to older age [CMBs (-) vs. CMBs $(+)$; $65.5 \pm 14.4$ vs. $71.1 \pm 11.9$ years; $p=0.003]$, arterial hypertension $(55.8 \%$ vs. $73.6 \% ; p=0.007)$, and the presence of WMH $(76.8 \%$ vs. $89.7 \% ; p=0.015$ ) (Table 1$)$. Also, the number of CMBs was positively correlated with increasing $\mathrm{WMH}$ score (correlation coefficient $r=0.430 ; p<0.001)$.

One hundred twenty-one $(53.8 \%)$ patients were classified as having a good functional outcome $(\mathrm{mRS} \leq 2)$ at discharge, and $142(63.1 \%)$ patients had good functional outcomes 6 months later. The group with a good functional outcome comprised younger patients with less severe stroke symptoms (lower initial NIHSS) and lower WMH scores than patients in the poor functional outcome group at both periods. Poor functional outcomes at 6 months were related to presence of previous stroke history than observed in those patients with good functional outcomes at 6 months (Table 2).

The presence of CMBs except was associated with a poor functional outcome at discharge [CMBs $(+)$ patients in poor vs. good functional group; $48.1 \%$ vs. $30.6 \% ; p=0.007$ by $\chi^{2}$ test] and 6 months [53.0\% vs. $30.3 \% ; p=0.001$ by $\chi^{2}$ test] (Table 2). After adjustment for confounding factors, only the presence of infratentorial CMBs was associated with a poor functional outcome at discharge (odds ratio, 2.6; 95\% confidence interval, $1.2-6.0 ; p=0.021$ ) and 6 months (odds ratio, $4.8 ; 95 \%$ confidence interval, 2.0-12.0; $p=0.001$ ) (Table 3). The poor functional outcome group more CMBs than did the good outcome group at 6 months $(3.0 \pm 5.5$ vs. $1.4 \pm 4.0 ; p=0.025$ by $t$ test $)$.

\section{DISCUSSION}

In this study of patients with acute ischemic stroke, CMBs tended to be associated with poor functional outcomes. In particular, the presence of infratentorial CMBs was clearly associated with a worse outcome not only in the early phase of ischemic stroke but also in the chronic phase.

To the best of our knowledge, we are the first to report an association between CMBs and functional recovery after stroke. 
Table 3: Associations of CMBs with poor functional outcomes ( $\mathrm{mRS}$ score $\geq 3$ )

\begin{tabular}{|c|c|c|c|c|c|c|}
\hline \multirow[t]{2}{*}{ Variable } & \multicolumn{3}{|c|}{ At discharge } & \multicolumn{3}{|c|}{ At 6 months } \\
\hline & Unadjusted & Adjusted $^{\mathrm{a}}$ & $p$ (adjusted) & Unadjusted & Adjusted $^{\mathbf{b}}$ & $p$ (adjusted) \\
\hline Presence of CMBs & $2.1(1.2-3.6)^{*}$ & $1.6(0.8-3.0)$ & 0.173 & $2.6(1.5-4.5)^{*}$ & $1.9(0.9-3.9)$ & 0.084 \\
\hline Lobar CMBs & $2.4(1.3-4.5)^{*}$ & $1.4(0.6-2.9)$ & 0.412 & $3.1(1.7-5.8)^{*}$ & $1.8(0.8-4.0)$ & 0.158 \\
\hline Deep CMBs & $1.4(0.8-2.6)$ & $1.1(0.5-2.5)$ & 0.768 & $1.6(0.9-3.0)$ & $1.2(0.5-3.0)$ & 0.631 \\
\hline Infratentorial CMBs & $2.5(1.3-5.2)$ & $2.6(1.2-6.0) *$ & $0.021 *$ & $3.6(1.8-7.4)^{* *}$ & $4.8(2.0-12.0)^{* *}$ & $0.001 * *$ \\
\hline
\end{tabular}

CMBs; cerebral microbleeds.

Data are odds ratio with $95 \%$ confidence interval in parentheses.

Analyses were performed with multiple logistic regression tests.

aAdjusted for age, history of previous stroke, WMH, initial scores on NIHSS.

${ }^{\mathrm{b}}$ Adjusted for age, sex, history of hypertension and previous stroke, WMH, initial scores on NIHSS.

Our findings are consistent with the proposition that microbleeds could be a general marker for underlying vascular disease, in particular cerebral amyloid angiopathy or hypertensive arteriolosclerosis, and as such may influence functional outcomes after stroke. ${ }^{5}$ In our study, the burden of CMBs was correlated with a higher WMH score. WMH, as a marker of cerebral small-vessel disease, can predict poorer functional outcomes after stroke. . $^{20,11}$ Severe white matter changes probably reflect chronically reduced tissue perfusion and cerebrovascular reactivity, which may lead to reduced penumbra survival after acute ischemic stroke.,21,22

Another possible explanation is that CMBs may reflect focal damage to brain tissue. Therefore, if they are located in areas important for motor regulatory functions and functional recovery after stroke such as the corticospinal tract, CMBs could interfere with recovery from functional deficits after stroke. We also found that especially infratentorial CMBs were associated with poor functional outcomes. Previous studies indicated that lobar microbleeds were associated with worse cognitive function. ${ }^{5,6}$ Different microbleed locations in the brain probably reflect differences in underlying etiologies ${ }^{23}$; deep or infratentorial microbleeds are related to hypertensive vasculopathy, whereas lobar microbleeds are thought to be a marker of pathologies associated with cerebral amyloid angiopathy, such as vascular deposition of amyloid or neuritic plaques. ${ }^{24,25} \mathrm{CMBs}$ in different locations may therefore reflect differences in cognition or functional recovery after stroke due to different underlying pathologies. Infratentorial CMBs can affect many densely packed fiber pathways, including all the ascending and descending pathways linking the brain with functional peripheral nerves and muscles. Therefore, in contrast to lobar or deep microbleeds, infratentorial CMBs may lead to disconnection of functionally important structures for recovery after stroke.

In our study, CMBs affect long-term functional outcomes much more than short-term outcomes after ischemic stroke. Functional outcomes during the acute period may be associated with other clinical factors such as age, subtype of ischemic stroke, location of the involved vessels, infarct volume, and other comorbid medical conditions such as infection or hyperglycemia, whereas functional recovery during the chronic period may be more affected by preexisting structural lesions such as previous stroke lesions, WMH, or even CMBs. This assertion implies that patients with preexisting brain damage have less ability to compensate functionally than those without preexisting damage.
These findings are supported by a previous study showing that WMH better predicted poorer functional outcomes in the chronic phase of ischemic stroke than in the acute phase. ${ }^{2}$

This study had several strengths but also some limitations. A major strength was that this study was a prospective cohort study, and therefore was not likely to have been affected by informational or survival rate bias. Second, the cohort at followup had a low censoring rate (13/238, or 5.4\%). However, several limitations should also be considered. First, because the number of microbleeds was highly skewed to both extremes, appropriate analysis of the burden of CMBs was difficult. Therefore, evaluation of the correlation between CMBs burden and functional outcome was challenging. We thus dichotomized microbleeds as present or absent in the logistic multivariable regression analysis. Second, excluding premorbid disability, dementia, and hemorrhagic stroke may have biased the results because these groups are most likely to have CMBs. Although we excluded patients with comorbid neurological diseases such as dementia or Parkinson's disease, patients with mild cognitive impairment may have been included. Mild cognitive impairment is known as a prodromal stage of dementia and CMBs are associated with Alzheimer disease pathology burden. Therefore, care should be taken when interpreting the results because premorbid mild cognitive decline may have confounded findings. Finally, because NIHSS tends to overestimate dominant hemisphere and anterior circulation ischemic strokes, it would also introduce a confounding factor when used as a surrogate marker of stroke severity.

In conclusion, infratentorial CMBs were significantly associated with worse functional outcomes not only in the early phase of ischemic stroke but also in the chronic phase. These findings suggest that the presence of CMBs can predict long-term poor functional outcome after acute ischemic stroke.

\section{Disclosures}

The authors report no disclosures.

\section{REFERENCES}

1. Johnston KC, Connors AF Jr., Wagner DP, et al. A predictive risk model for outcomes of ischemic stroke. Stroke. 2000; 31(2):448-55. 
2. Kang HJ, Stewart R, Park MS, et al. White matter hyperintensities and functional outcomes at 2 weeks and 1 year after stroke. Cerebrovasc Dis. 2013;35(2):138-45.

3. Meijer R, Ihnenfeldt DS, de Groot IJ, et al. Prognostic factors for ambulation and activities of daily living in the subacute phase after stroke. A systematic review of the literature. Clin Rehabil. 2003;17(2):119-29.

4. Koennecke HC. Cerebral microbleeds on MRI: prevalence, associations, and potential clinical implications. Neurology. 2006; 66(2):165-71.

5. Poels MM, Ikram MA, van der Lugt A, et al. Cerebral microbleeds are associated with worse cognitive function: the Rotterdam Scan Study. Neurology. 2012;78(5):326-33.

6. Werring DJ, Gregoire SM, Cipolotti L. Cerebral microbleeds and vascular cognitive impairment. J Neurol Sci. 2010; 299(1-2):131-5.

7. Tang WK, Chen JY, Lu JY, et al. Cerebral microbleeds and depression in lacunar stroke. Stroke. 2011;42(9):2443-6.

8. Ovbiagele B, Saver JL, Sanossian N, et al. Predictors of cerebral microbleeds in acute ischemic stroke and TIA patients. Cerebrovasc Dis. 2006;22(5-6):378-83.

9. Koton S, Schwammenthal Y, Merzeliak O, et al. Cerebral leukoaraiosis in patients with stroke or TIA: clinical correlates and 1-year outcome. Eur J Neurol. 2009;16(2):218-25.

10. Miyao S, Takano A, Teramoto J, et al. Leukoaraiosis in relation to prognosis for patients with lacunar infarction. Stroke. 1992; 23(10):1434-8.

11. Viswanathan A, Gschwendtner A, Guichard JP, et al. Lacunar lesions are independently associated with disability and cognitive impairment in CADASIL. Neurology. 2007;69(2):172-9.

12. Brott T, Adams HP Jr., Olinger CP, et al. Measurements of acute cerebral infarction: a clinical examination scale. Stroke. 1989;20 (7):864-70.

13. van Swieten JC, Koudstaal PJ, Visser MC, et al. Interobserver agreement for the assessment of handicap in stroke patients. Stroke. 1988;19(5):604-7.
14. Greenberg SM, Vernooij MW, Cordonnier C, et al. Cerebral microbleeds: a guide to detection and interpretation. Lancet Neurol. 2009;8(2):165-74.

15. Vernooij MW, van der Lugt A, Ikram MA, et al. Prevalence and risk factors of cerebral microbleeds: the Rotterdam Scan Study. Neurology. 2008;70(14):1208-14.

16. Scheltens $P$, Barkhof F, Leys D, et al. A semiquantitative rating scale for the assessment of signal hyperintensities on magnetic resonance imaging. J Neurol Sci. 1993;114(1):7-12.

17. Tissue plasminogen activator for acute ischemic stroke. The National Institute of Neurological Disorders and Stroke rt-PA Stroke Study Group. N Engl J Med. 1995;333(24):1581-7.

18. Liou LM, Chen CF, Guo YC, et al. Cerebral white matter hyperintensities predict functional stroke outcome. Cerebrovasc Dis. 2010;29(1):22-7.

19. Biffi A, Halpin A, Towfighi A, et al. Aspirin and recurrent intracerebral hemorrhage in cerebral amyloid angiopathy. Neurology. 2010;75(8):693-8.

20. Soo YO, Yang SR, Lam WW, et al. Risk vs benefit of antithrombotic therapy in ischaemic stroke patients with cerebral microbleeds. J Neurol. 2008;255(11):1679-86.

21. Ay H, Arsava EM, Rosand J, et al. Severity of leukoaraiosis and susceptibility to infarct growth in acute stroke. Stroke. 2008; 39(5):1409-13.

22. Brown WR, Thore CR. Review: cerebral microvascular pathology in ageing and neurodegeneration. Neuropathol Appl Neurobiol. 2011;37(1):56-74.

23. Poels MM, Vernooij MW, Ikram MA, et al. Prevalence and risk factors of cerebral microbleeds: an update of the Rotterdam scan study. Stroke. 2010;41(10):S103-6.

24. Gilbert JJ, Vinters HV. Cerebral amyloid angiopathy: incidence and complications in the aging brain. I. Cerebral hemorrhage. Stroke. 1983;14(6):915-23.

25. Greenberg SM, Eng JA, Ning M, et al. Hemorrhage burden predicts recurrent intracerebral hemorrhage after lobar hemorrhage. Stroke. 2004;35(6):1415-20. 